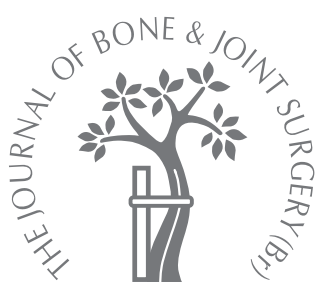

M. R. G. Menon, J. L. Walker, C. M. Court-Brown

From the New Royal Infirmary of Edinburgh, Edinburgh, Scotland

M. R. G. Menon, FRCSC Orthopaedic Surgeon J. L. Walker, MBChB, FY1 Orthopaedic Surgery - C. M. Court-Brown, MD, FRCSEd(Orth), Professor of Orthopaedic Trauma Royal Infirmary of Edinburgh, Little France, Edinburgh EH16 4SU, UK.

Correspondence should be sent to Professor C. M. Court-Brown; e-mail: courtbrown@aol.com

(C)2008 British Editorial Society of Bone and Joint Surgery doi:10.1302/0301-620X.90B11. $21163 \$ 2.00$

$J$ Bone Joint Surg [Br] 2008;90-B:1482-6.

Received 16 April 2008; Accepted 6 June 2008

\title{
The epidemiology of fractures in adolescents with reference to social deprivation
}

\begin{abstract}
A relationship between social deprivation and the incidence of fracture in adolescents has not previously been shown. We have used a complete fracture database to identify adolescents who sustained fractures in 2000. The 2001 Scottish census was used to obtain age-specific population and deprivation data according to the Carstairs score. Regression analysis determined the relationship between the incidence of fractures and social deprivation.

We analysed 1574 adolescents with fractures (1083 male, 491 female). The incidence of fractures in this group was 21.8 per thousand (31.0 male, 13.1 female). Social deprivation predicted the incidence in adolescent males and females. The incidence of fractures of the proximal upper limb and distal radius in females was overwhelmingly influenced by socioeconomic factors. Males of $\mathbf{1 5}$ to $\mathbf{2 0}$ years of age were more likely to sustain fractures of the hand and carpus if they lived in economically depressed neighbourhoods.
\end{abstract}

The epidemiology of paediatric and adult fractures has been examined extensively, ${ }^{1-6}$ but the adolescent group which spans these two categories has received very little attention. Most paediatric studies include patients up to 14 or 16 years of age while adult studies usually start at 14 years. It has been acknowledged that there is an increase in the incidence of fractures in young males, ${ }^{1,2}$ but the precise epidemiology of fractures in adolescents has not been studied. We therefore undertook an epidemiological study of fractures in adolescents with particular reference to the role of social deprivation in this group of patients. It has been shown that this is an important factor in childhood injury ${ }^{7-9}$ and we hypothesised that it was also a major factor in fractures in adolescents.

\section{Patients and Methods}

All patients with fractures in the City of Edinburgh, Midlothian and East Lothian areas, present to one of two hospitals for diagnosis and treatment. The regional paediatric hospital admits patients up to 14 years of age and the adult trauma centre treats adults. All patients with fractures seen in the two Accident and Emergency Departments are referred to fracture clinics where the diagnoses are confirmed and the fractures treated. Prospectively collected databases of all inpatients and outpatients with fractures are kept in each hospital. For the purposes of this study, all patients who presented to both hospitals in the year 2000 were examined. To determine the incidence of fractures we used identical methods to those described in previously published papers on the epidemiology of fractures in children and adults. ${ }^{1,2}$ All radiographs were reviewed by an orthopaedic surgeon (CMC-B) or a research fellow to minimise diagnostic error. The site of the fracture was recorded using standard anatomical descriptions and all fractures were listed separately. We excluded skull and rib fractures from the analysis. All the fractures in the adolescent groups were incorporated in a single database.

The fractures were assigned to one of five groups according to the $\mathrm{AO}$ classification. ${ }^{10}$ Group A included fractures of the distal radius ( $\mathrm{AO} 23$ ), group $\mathrm{B}$ those of the hand and wrist ( $\mathrm{AO} 24$ to 26), group $\mathrm{C}$ fractures of the pelvis and lower limb (AO 6, 31 to 43), group D those of the foot and ankle ( $\mathrm{AO} 44$, 80 to 89 ) and group $\mathrm{E}$, those of the clavicle and proximal upper limb (11 to 22).

We defined the adolescent population as being those patients aged between ten and 19 years, which we subdivided into male and female junior (10 to 14 years) and senior groups (15 to 19 years).

Comparative data for our group was obtained from the Scottish 2001 census $^{11}$ which provided population statistics by age 
Table I. Fracture-specific incidence in adolescents, children and adults

\begin{tabular}{|c|c|c|c|c|c|c|}
\hline & \multicolumn{2}{|c|}{ Adolescents (10 to 19) } & \multicolumn{2}{|c|}{ Children (0 to 13) } & \multicolumn{2}{|c|}{ Adults ( $\geq 14)$} \\
\hline & $n / 10^{5}$ & $\begin{array}{l}\text { Gender } \\
\text { (M:F; \%) }\end{array}$ & $n / 10^{5}$ & $\begin{array}{l}\text { Gender } \\
\text { (M:F; \%) }\end{array}$ & $n / 10^{5}$ & $\begin{array}{l}\text { Gender } \\
\text { (M:F; \%) }\end{array}$ \\
\hline Distal radius & 659.0 & $63 / 38$ & 689.7 & $53 / 47$ & 195.2 & $31 / 69$ \\
\hline Finger phalanges & 439.9 & $72 / 28$ & 294.7 & $65 / 35$ & 107.3 & $68 / 32$ \\
\hline Metacarpus & 405.3 & $90 / 10$ & 111.8 & $79 / 21$ & 130.3 & $85 / 15$ \\
\hline Clavicle & 139.8 & $88 / 12$ & 137.9 & $66 / 34$ & 36.5 & $70 / 30$ \\
\hline Metatarsus & 132.7 & $66 / 34$ & 99.3 & $53 / 47$ & 75.4 & $43 / 57$ \\
\hline Ankle & 118.6 & $76 / 24$ & 60.6 & $57 / 43$ & 100.8 & $47 / 53$ \\
\hline Toe phalanges & 110.1 & $64 / 36$ & 63.7 & $46 / 54$ & 39.6 & $66 / 34$ \\
\hline Carpus & 69.2 & $80 / 20$ & 19.9 & $79 / 21$ & 29.7 & $72 / 28$ \\
\hline Forearm diaphysis & 63.5 & $80 / 20$ & 111.8 & $63 / 37$ & 13.8 & $64 / 36$ \\
\hline Proximal forearm & 55.1 & $46 / 54$ & 59.6 & $42 / 58$ & 55.5 & $46 / 54$ \\
\hline Tibial diaphysis & 52.2 & $73 / 27$ & 44.9 & $65 / 35$ & 21.5 & $61 / 39$ \\
\hline Distal tibia & 35.3 & $64 / 36$ & 33.4 & $69 / 31$ & 7.9 & $57 / 43$ \\
\hline Proximal humerus & 29.7 & $43 / 57$ & 38.7 & $32 / 68$ & 63.0 & $30 / 70$ \\
\hline Distal humerus & 32.5 & $61 / 39$ & 166.2 & $57 / 43$ & 5.8 & $29 / 71$ \\
\hline Spine & 12.7 & $78 / 22$ & 5.2 & $60 / 40$ & 7.5 & $62 / 38$ \\
\hline Proximal tibia & 11.3 & $75 / 25$ & 4.2 & $100 / 0$ & 13.3 & $54 / 46$ \\
\hline Humeral diaphysis & 11.3 & $50 / 50$ & 5.2 & $80 / 20$ & 12.9 & $42 / 58$ \\
\hline Patella & 9.9 & $71 / 29$ & 4.2 & $75 / 25$ & 10.7 & $44 / 56$ \\
\hline Femoral diaphysis & 8.5 & $100 / 0$ & 16.7 & $69 / 31$ & 10.3 & $36 / 64$ \\
\hline Pelvis & 8.5 & $83 / 17$ & 4.2 & $75 / 25$ & 17.0 & $30 / 70$ \\
\hline Calcaneus & 7.1 & $80 / 20$ & 2.1 & $100 / 0$ & 13.7 & $78 / 22$ \\
\hline Midfoot & 5.7 & $100 / 0$ & 4.2 & $75 / 25$ & 5.0 & $48 / 52$ \\
\hline Talus & 5.7 & $75 / 25$ & 1.0 & $100 / 0$ & 3.2 & $82 / 18$ \\
\hline Proximal femur & 5.7 & $100 / 0$ & 1.0 & $100 / 0$ & 129.4 & $26 / 74$ \\
\hline Distal femur & 2.8 & $100 / 0$ & 5.2 & $80 / 20$ & 4.5 & $33 / 67$ \\
\hline Scapula & 2.8 & $100 / 0$ & 0 & ------ & 3.2 & $59 / 41$ \\
\hline Total & 2430.2 & $72 / 28$ & 1986.5 & $58 / 42$ & 1113.3 & $50 / 50$ \\
\hline
\end{tabular}

and gender within each postcode sector in our defined area. The 2001 census gave population statistics closest in date to our data from 2000 and was therefore used to determine the overall and group-specific incidence of fractures.

The Carstairs and Morris index ${ }^{12}$ was used to assess social deprivation. This is commonly used as an indicator of socio-economic status in health research in the United Kingdom. The scores are published for each postcode sector in Scotland. ${ }^{13}$ The Carstairs deprivation category is a categorical variable derived from the index of deprivation with values ranging from 1 (most affluent) to 7 (most deprived). A Carstairs score was allocated to each adolescent patient according to their home postcode at the time of injury. The database of fractures in adolescents, the 2001 census population statistics and the Carstairs scores were used to determine the gender, postcode and age-groupspecific incidence of fractures in theadolescent population for the year 2000 .

Statistical analysis. Regression analysis was used to determine the age-group and gender-specific influences of social deprivation on the incidence of fractures and to determine the influence of social deprivation on specific patterns of fracture. Analysis was performed using the incidence of fracture in each postcode sector as the outcome variable and the Carstairs score as the predictor variable. We then performed the same regression procedure on each of our four cohorts grouped by age and gender. Values were weighted by the size of the population in each postcode sector. A p-value of $<0.05$ was considered to be significant.

\section{Results}

Analysis of the database showed that there were 1706 fractures in 1574 patients (1083 males, 491 females). The overall incidence was 24.3 per 1000 per year and $72 \%$ occurred in males (Table I). Curves of the incidence of the whole population in the year 2000 (Fig. 1) showed that male adolescents had an incidence of 38.3 per 1000 per year and that this was second only to the incidence of fractures in women over 80 years of age (45.5 per 1000 per year). A progressive rise was found in fractures up to 13 years of age in boys and to 11 years in girls. After this there was a decline in incidence in both genders although this was more pronounced in females and at 19 years of age the incidence in males was 3.6 times that in females (Fig. 2).

Comparison of the incidence of different fractures in the adolescent group with that of the paediatric group (0 to 13 years) and the adult group ( $>14$ years) showed that the most common fractures seen in adolescence were those of the distal radius and ulna, phalangesin the hand, metacarpus, clavicle and metatarsus (Table I). These accounted for $73.6 \%$ of all adolescent fractures and $73 \%$ of them occurred in males. In addition, fractures of the carpus, 


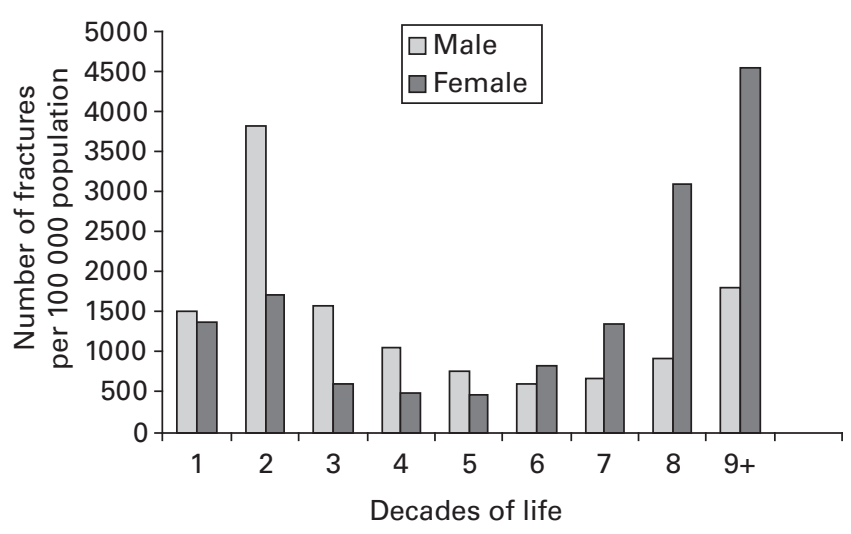

Fig. 1

Bar chart showing the distribution of fractures in the whole population.

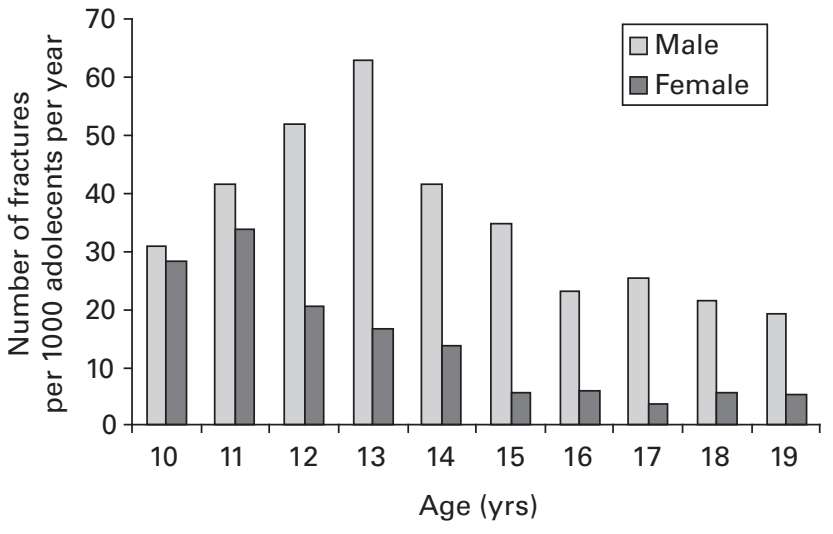

Fig. 2

Bar chart showing the distribution of fractures in the adolescent population.
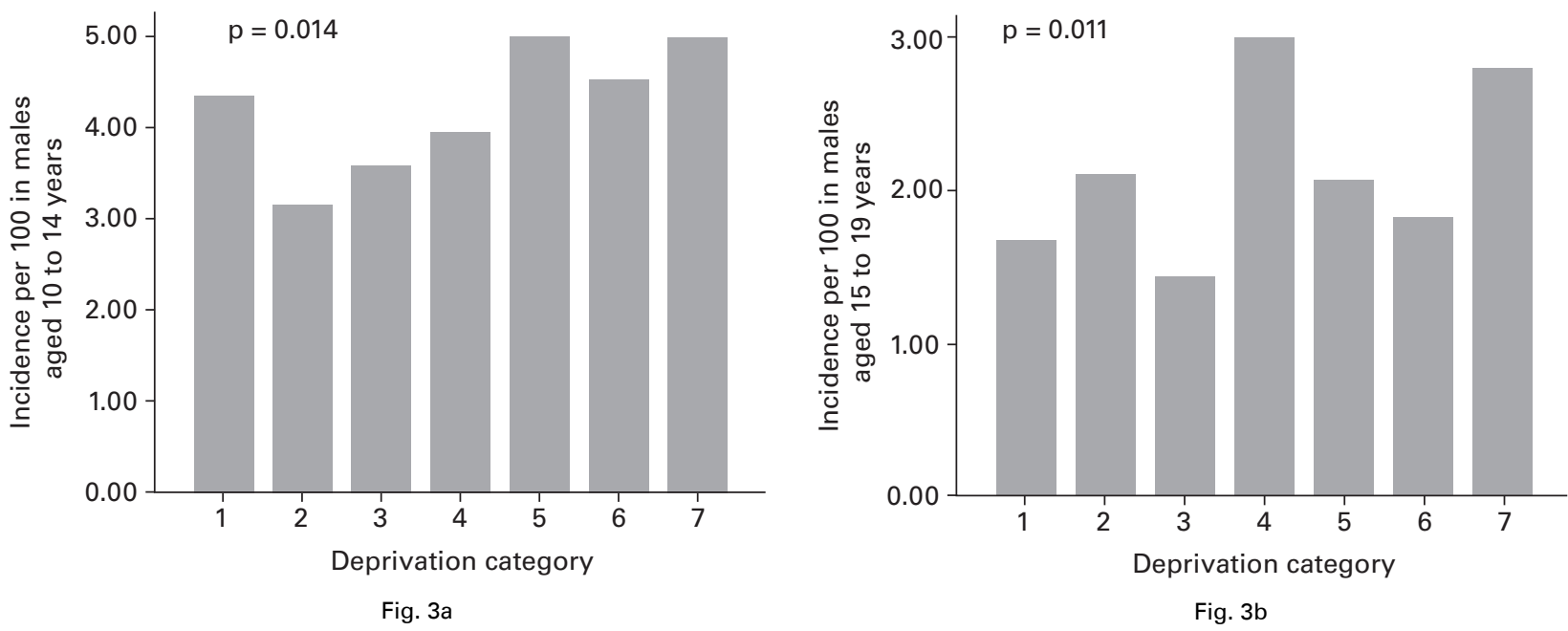

Bar chart showing the incidence of fractures for the different deprivation categories in male adolescents from a) 10 to 14 and b) 15 to 19 years of age.

metacarpus and phalanges in the hand were found to be particularly common in adolescence, with $34.6 \%$ of all fractures of the hand occurring in this age group.

The fracture incidence for each deprivation category for male and female junior and senior adolescents is shown in Figures 3 and 4 . Weighted linear regression analysis showed a significant relationship between social deprivation and fracture incidence in both junior $(\mathrm{p}=0.014)$ and senior adolescent males $(p=0.011)$ and a highly significant relationship in senior adolescent females $(\mathrm{p}<0.001)$. However, there was no significant relationship in junior adolescent females $(p=0.08)$. Regression analysis also showed that the Carstairs index significantly predicted fracture incidence in our entire population $(\mathrm{p}=0.001$; coefficient $=0.09$ ).
With regard to specific types of fracture we found that social deprivation was an independent and significant predictor of risk in fractures of the hand (group B) in senior adolescent males $(\mathrm{p}<0.001)$, fractures of the upper limb (group E) in junior adolescent males $(p=0.009)$ and in fractures of the upper limb (group E) and distal radius (group A) in senior adolescent females $(p<0.001)$. The results of weighted regression analysis using the Carstairs score to predict specific types of fracture by age, group and gender are shown in Table II.

\section{Discussion}

We suspect that fractures in adolescents have received little attention in the medical literature mainly because such injuries are traditionally grouped by age and are presented 

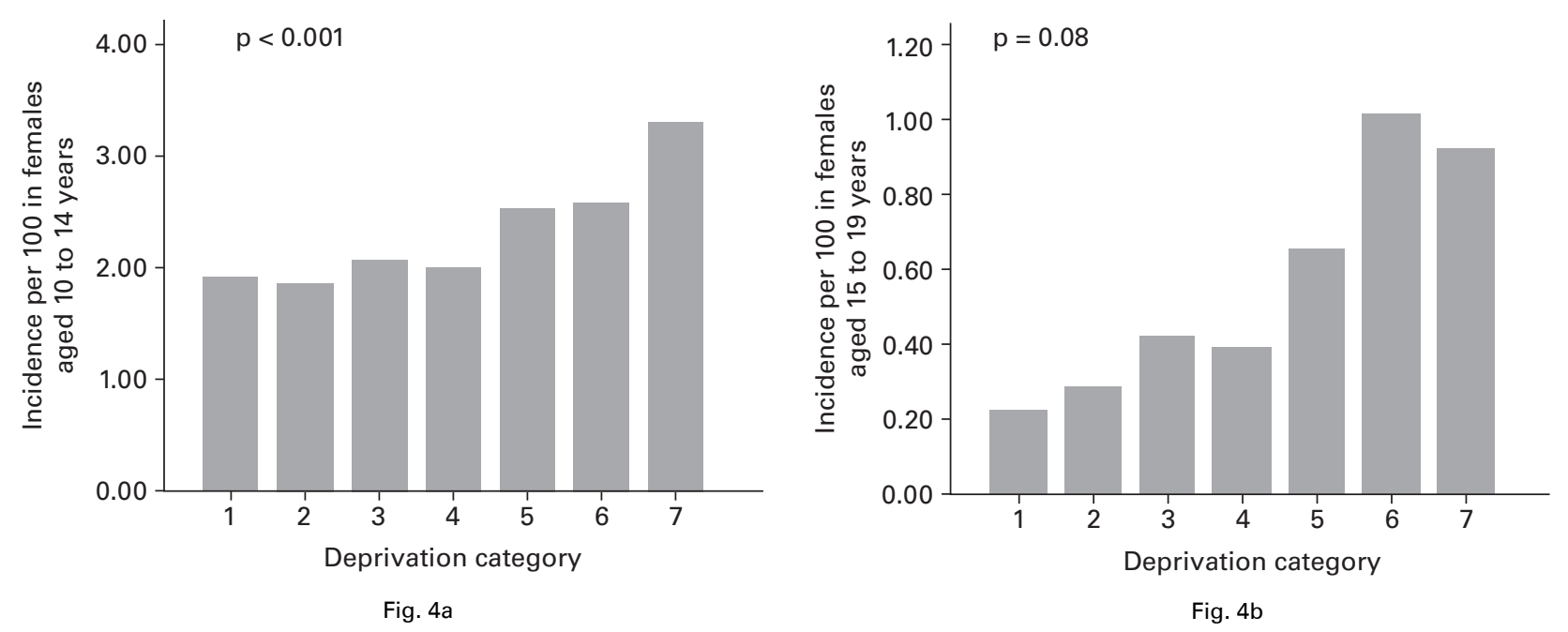

Bar chart showing the incidence of fractures for the different deprivation categories in female adolescents from a) 10 to 14 and b) 15 to 19 years of age.

\begin{tabular}{|c|c|c|c|c|c|c|}
\hline \multirow[b]{2}{*}{ Group } & \multirow[b]{2}{*}{ AO injury codes } & \multirow[b]{2}{*}{ Number } & \multicolumn{2}{|c|}{ Males by age (yrs) } & \multicolumn{2}{|c|}{ Females by age (yrs) } \\
\hline & & & 10 to 14 & 15 to 19 & 10 to 14 & 15 to 19 \\
\hline All & All & 1574 & $+0.14(0.06)^{*}$ & $+0.09(0.26)$ & $+0.07(0.04)$ & $+0.06(0.02)^{*}$ \\
\hline$A$ & 23 & 452 & $+0.16(0.27)$ & $-0.11(0.14)$ & $+0.23(0.27)$ & $+0.26(0.08)^{*}$ \\
\hline B & 24 to 26 & 597 & $+0.48(0.31)$ & $+1.03(0.26)$ & $+0.17(0.16)$ & $+0.08(0.01)$ \\
\hline $\mathrm{C}$ & 6,31 to 43 & 156 & $+0.05(0.15)$ & $-0.16(0.12)$ & $+0.12(0.08)$ & $+0.08(0.05)$ \\
\hline $\mathrm{D}$ & 44,70 to 89 & 161 & $+0.34(0.18)$ & $+0.13(0.13)$ & $+0.11(0.14)$ & $+0.07(0.06)$ \\
\hline$E$ & 06,10 to 22 & 208 & $+0.48(0.18)^{*}$ & $-0.12(0.12)$ & $-0.04(0.15)$ & $+0.21(0.06)^{*}$ \\
\hline
\end{tabular}

as being either paediatric or adult. In a recent analysis of the fracture distribution curves seen in children (0 to 15 years), Rennie et $\mathrm{al}^{2}$ drew attention to the fact that in a number of such fractures there was a unimodal incidence peak in late childhood which probably extended into adulthood. An arbitrary division of fractures into paediatric and adult prevents an understanding of the frequency of these particular injuries, but it is clear from Table I that there are categories of fracture which are commonly seen in adolescence and those which are less common in childhood and in the adult years. The most obvious examples are those of the hand, metatarsus, phalanges of the foot, ankle, tibial diaphysis and spine.

There are a number of other fractures which are more common in childhood. The most obvious example is fracture of the distal humerus which has a very high incidence in childhood and a low incidence in the adult. Table I shows that other examples include fractures of the diaphysis of the forearm and distal tibia. Additionally, Table I indicates that a number of fractures have a low incidence in childhood, but that this steadily increases in adolescence. These include fractures involving the humeral diaphysis, patella, pelvis and calcaneus. It is interesting to note that fracture of the proximal forearm has a similar incidence at all ages.

The other striking feature of fractures in adolescents as opposed to those in children or adults is their predominance in males. Almost $75 \%$ occur in males (Table I). This is reflected in the mode of injury with $39.8 \%$ of adolescents sustaining their fractures in sporting activities or in assaults or fights, contrasting with $20.2 \%$ in children and $24.9 \%$ in adults. Analysis of the fractures of the metacarpus and phalanges of the hand showed that $28 \%$ were reported to occur in sports and $37.2 \%$ as a result of an assault or fight. The predominance of fractures in males is highlighted by the fact that 13-year-old boys have the highest age-related incidence of fractures at 62.9 per 1000 per year. This is only slightly less than the figure of $67.4 / 1000 / y e a r$ in women aged 90 years or older. ${ }^{1}$

The relationship between social deprivation and fractures in adolescents is not surprising but has not previously been demonstrated. All the fractures which are related to social deprivation occur in the upper limb. We believe that the mode of injury is important. Junior adolescent females do not show an association between social deprivation and fracture and it is interesting to note that $42.5 \%$ of fractures in this group 
occur after falls, with only $9.1 \%$ the result of an admitted assault or fight. In the other three adolescent groups there was an association between social deprivation and fracture. A review of the literature gives some evidence of a relationship between social deprivation and the mode of injury causing a fracture. Court-Brown and Brydone ${ }^{14}$ examined the relationship between tibial diaphyseal fractures and social deprivation and found that the most affluent patients tended to sustain their fractures in sporting activities and the most deprived from an assault or direct blow. Horton, Dias and Burke ${ }^{15}$ also failed to show an association between sport-related hand injury and social deprivation. We suggest that the mode of injury is the main causative factor in the relationship between social deprivation and fracture.

There are very few studies on fractures in adolescents and none detailing their epidemiology. However, Konstantynowicz et al, ${ }^{16}$ in a study of Polish adolescents aged between 16 and 20 years, showed a similar distribution of types of fracture and also reported an association between fractures in adolescents and those in other family members suggesting patterns of learned behaviour. In a recent study of social deprivation and hand injury Horton et $\mathrm{al}^{15}$ showed that social deprivation was significantly associated with hand trauma and that the association was most marked in older children and adults. They showed that fractures of the hand, sprains and ligament injuries had the strongest association with social deprivation.

\section{Supplementary material}

$\because$ A further opinion by Mr J. Hobby is available with e the electronic version of this article on our website at www.jbjs.org.uk

We thank Dr R. Elton, PhD, medical statistician, for his assistance.

No benefits in any form have been received or will be received from a commercial party related directly or indirectly to the subject of this article.

\section{References}

1. Court-Brown CM, Caesar B. Epidemiology of adult fractures: a review. Injury 2006;37:691-7.

2. Rennie L, Court-Brown CM, Mok JY, Beattie TF. The epidemiology of fractures in children. Injury 2007;38:913-22.

3. Lyons RA, Delahunty AM, Kraus D, et al. Children's fractures: a population based study. Inj Prev 1999;5:129-32.

4. Cooper C, Dennison EM, Leufkens HG, Bishop N, van Staa TP. Epidemiology of childhood fractures in Britain: a study using the general practice research database. J Bone Min Res 2004;19:1976-81.

5. Johansen A, Evans RJ, Stone MD, et al. Fracture incidence in England and Wales: a study based on the population of Cardiff. Injury 1997;28:655-60.

6. Lyons RA, Sellstrom E, Delahunty AM, Loeb M, Varilo S. Incidence and cause of fractures in European districts. Arch Dis Child 2000;82:452-5.

7. Stark AD, Bennet GC, Stone DH, Chishti P. Association between childhood fractures and poverty: population based study. BMJ 2002;324:457.

8. Lyons RA, Delahunty AM, Heaven $\mathbf{M}$, et al. Incidence of childhood fractures in affluent and deprived areas: population based study. BMJ 2000;320:149.

9. Beattie TF, Gorman DR, Walker JJ. The association between deprivation levels, attendance rate and triage category of children attending a children's accident and emergency department. Emerg Med J 2001;18:110-11.

10. Müller ME, Nazarian S, Koch P, Schatzker J. The comprehensive classification of fractures of long bones. Berlin: Springer-Verlag, 1990.

11. No authors listed. Source 2001 Census data supplied by the General Register Office for Scotland. (C) Crown Copyright. Edinburgh: General Register Office for Scotland 2001: http://www.gro-scotland.gov.uk/census/censushm/index.htm/ (date last accessed 19 June 2008).

12. Carstairs V, V, Morris R. Deprivation and health in Scotland. Health Bull 1990;48:162-75.

13. McLoone P. Carstairs scores for Scottish poscode sectors from the 2001 Census. Glasgow: MRC Social \& Public Health Sciences Unit, 2004.

14. Court-Brown CM, Brydone A. Social deprivation and adult tibial diaphyseal fractures. Injury 2007;38:750-4.

15. Horton TC, Dias JJ, Burke FD. Social deprivation and hand injury. J Hand Surg Eur Vol 2007;32:256-61.

16. Konstantynowicz J, Bialokoz-Kalinowska I, Motkowski R, et al. The characteristics of fractures in Polish adolescents aged 16-20 years. Osteoporosis Int 2005;16:1397-403. 